\title{
Effects of $\mathrm{NaOCl}$ treatment on in vitro germination of seeds of a rare endemic plant, Oreorchis coreana Finet
}

\author{
Kee-Hwa Bae $\cdot$ Myoung Suk Ko $\cdot$ Mi Hyun Lee $\cdot$ Nam Young Kim $\cdot$ Jae Mo Song $\cdot$ Gwanpil Song
}

Received: 18 January 2013 / Accepted: 31 January 2013

(C) Korean Society for Plant Biotechnology

\begin{abstract}
Oreorchis coreana Finet is threatened globally by over-collection from its natural habitats for horticultural purposes. Its rarity in nature makes this plant one of the most endangered species in Korea. In this study, we investigated the effects of sodium hypochlorite $(\mathrm{NaOCl})$ on orchid seed viability and seed germination. An in vitro bioassay swelling test using immature seeds was compared with a standard chemical procedure using triphenyl tetrazolium chloride (TTC) to test seed viability. In general, the bioassay was more appropriate for estimating embryo viability after a prolonged pre-treatment (more than $1 \mathrm{~h}$ ) in $1 \% \mathrm{NaOCl}$, a surface sterilant often used to enhance germination of seeds of terrestrial plants. Therefore, an efficient method for investigating in vitro swelling of immature seeds is urgently needed. We established a method for determining the viability and swelling of $O$. coreana seeds via in vitro examination of immature seeds. Treatment of immature seeds with $1 \% \mathrm{NaOCl}$ for 10 min greatly enhanced the extent of swelling of immature zygote embryos when compared to
\end{abstract}

K.-H. Bae

Hongcheon Institute of Medicinal Herb, 101 Yeonbong-ri, Hongcheon-eup, Hongcheon, Gangwon, 250-930, Korea

M. S. Ko

Jeju Biodiversity Research Institute, Jeju Technopark, Seogwipo, 699-943, Korea

M. H. Lee

Plant Quarantine Technology Center, Suwon 443-440, Korea

N. Y. Kim

Department of Horticulture and Education, Korea National Arboretum. Pocheon, Gyeonggi 487-821, Korea

J. M. Song

Nature Environment Research Office of Gangwon Province,

Hongcheon, Gangwon, 250-884, Korea

G. Song $(\bowtie)$

Jeju Environment Research Institute, Rm 311, B1 Center, Jeju Tourism College, Jeju 690-791, Korea

e-mail: gwanpill@hanmail.net untreated seeds. These data obtained here appear to be comparable to viability and swelling that occurs in $O$. coreana seeds via asymbiotic germination.

Keywords Germination, Orchid, Oreorchis coreana Finet., Seed viability

\section{Introduction}

Oreorchis coreana Finet (Orchidaceae) was reported as a new species by Finet in 1908. In 1935, however, Maekawa described a new genus, Dipiolabellum, based on that species because it lacked the caudicle that is a diagnostic character in Oreorchis. Since Maekawa's treatment, this species has been reported by some authors as endemic to Korea (Lee 1996; Lee 1984; Paik 1999), whereas Lee (2006) has either retained it as a species or treated it as a subspecies of Oreorchis. The species is classified as VU (Vulnerable) in the IUCN Red List categories (Lee and Choi 2006; IUCN 2009) and $O$. coreana is found in only an extremely small site (Gotchawal province) on Jeju Island. The stems of $O$. coreana are $18 \sim 30 \mathrm{~cm}$ in high. The flowers are showy with white or brown coloration on the surface of petals and sepals (Maekawa 1935; Fig. 2A).

In vitro propagation techniques have been widely used for the conservation of threatened orchid species (Stewart and Kane 2006a; Stewart and Kane 2006b; Stewart and Kane 2007; Bae et al. 2009; Dutra et al. 2009; Suzuki et al. 2009; Bae et al. 2010; Bae and Choi 2011). Although this approach has been used for a long time, scientific research on the in vitro germination of orchid seeds is limited, especially when considering the large number of species in the family. Moreover, most of the published studies have focused on those species that are partial to terrestrial habits and/or temperate climates.

In a previous paper, we reported that sodium hypochlorite 
(NaOCl) treatment, a common method for disinfection of plant materials, was very effective at stimulating in vitro germination of $O$. coreana seeds. The effectiveness of disinfection solution such as $\mathrm{NaOCl}$ and calcium hypochlorite $\left(\mathrm{Ca}(\mathrm{ClO})_{2}\right)$ for stimulation of germination of orchid seeds has been reported in other species (Malmgren 1996; Miyoshi and Mii 1998; Bae et al. 2009; Bae et al. 2010, Bae and Choi 2011). The mechanism underlying this stimulating effect on germination of orchid seeds is not well under stood (Harvais and Hadley 1967).

In vitro germination of seeds can be an efficient way to propagate the $O$. coreana species, but micropropagation of Oreorchis spp. via in vitro culture of immature seeds has not been reported previously. Therefore, the aims of this study were first to describe seed viability and embryo development in this species and then to evaluate and establish a method for in vitro culture of immature seeds from $O$. coreana.

\section{Materials and methods}

Plant materials and culture conditions

Capsules of $O$. coreana were collected immediately prior to dehiscence from a single population near Aewol Gotchawal province (Fig. 1A, B), Jeju Island, in late October 2009 (immature capsules from six plants, Fig. 2B), and early November 2009 (mature capsules from four plants). All orchids have an obligate relationship with mycorrhizal fungi during seed germination and development (Rasmussen 1992). O. coreana also has an association with a mycorrhizal fungus in the root (Fig. 2C, D). Following collection, capsules were placed in paper bags and stored at room temperature for 5 days in a cardboard box, and then transferred to a domestic refrigerator and stored at $5^{\circ} \mathrm{C}$ until used for germination trials. Initially, the seeds were immersed in deionized, sterilized water and agitated for 30 min. Seeds were then treated with $30 \mathrm{~mL} 1 \% \mathrm{NaOCl}$ in deionized water $(\mathrm{v} / \mathrm{v})$ for $10 \mathrm{~min}$, followed by three $30 \mathrm{~s}$ rinses in deionized, sterilized water. Seeds were left in the final rinse water until transfer to half strength MS medium (Murashige and Skoog 1962). Two basal media were used in this study: 1/2 Phytomax Orchid Maintenance (POM), POM, 1/2 MS, and MS media without plant growth regulators. All media were supplemented with $20 \mathrm{~g} \mathrm{~L}^{-1}$ sucrose and $\mathrm{pH}$ was adjusted to 5.5 with $0.1 \mathrm{M} \mathrm{KOH}$ before the addition of $3.0 \mathrm{~g} \mathrm{~L}^{-1}$ Gelrite. Media were autoclaved at $117.7 \mathrm{kPa}$ and $121^{\circ} \mathrm{C}$ for $15 \mathrm{~min}$. The cultures were maintained in a growth room at $20 \pm 2^{\circ} \mathrm{C}$.

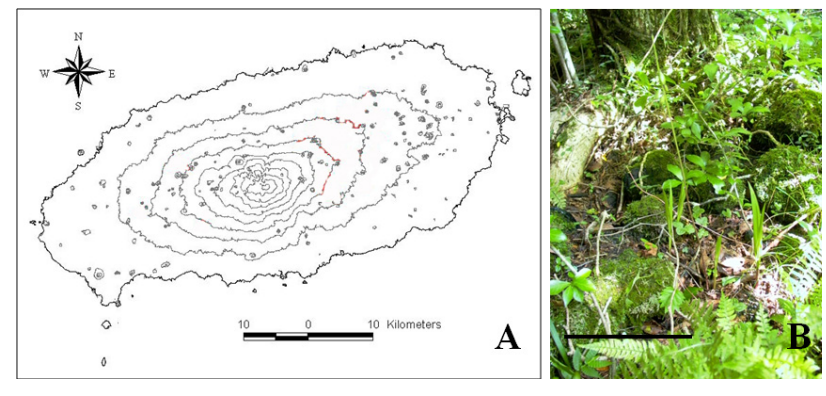

Fig. 1 Collected area and habitate of $O$. coreana. A: Map of Jeju island (Red line was Aewol Gotchawal), B: Habitate of $O$. coreana
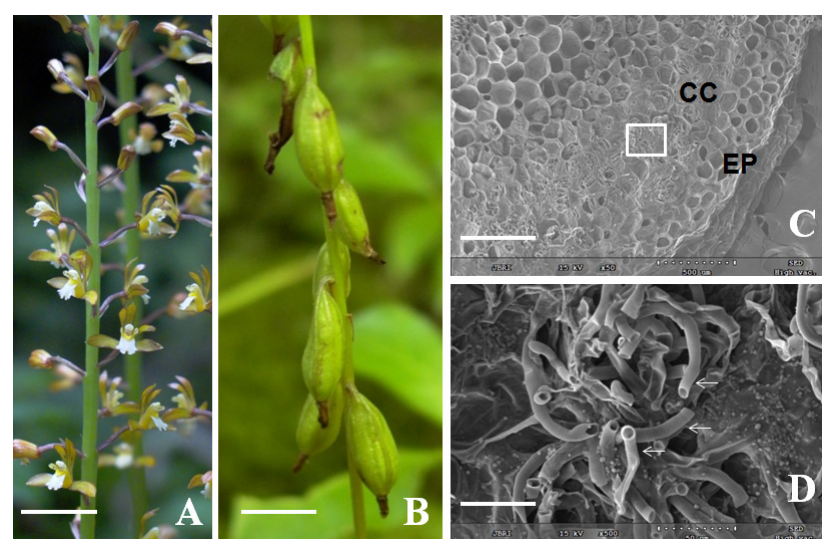

Fig. 2 Morphology and anatomical studies showing association of the fungus in the root of $O$. coreana. A: flowers. B: 4 month old fruits. C: The entry of the fungal hyphae through the cortical cell, Bars indicate 500 um. D: Closed view of white square, Bars indicate 50 um. EP: Epidermis cell, CC: Cortical cell, White arrows indicated fungal hyphae

Viability test for seeds treated with sodium hypochlorite

Immature seeds of $O$. coreana were treated for $0,10,30$, or $60 \mathrm{~min}$ with $1 \% \mathrm{NaOCl}$ and then rinsed three times with sterile water. Seed viability was evaluated using the Tetrazolium test (Lakon 1949), consisting of a solution of 2,3,5-triphenyltetrazolium chloride (TCC), which stains viable embryos red. Seeds were immersed in $1 \%$ TCC and stored in the dark for $24 \mathrm{~h}$ at $30^{\circ} \mathrm{C}$. Samples of 1,000 seeds per fruit were analyzed under an optical microscope before and after surface sterilization. The percentage of viable seeds was calculated by dividing the number of viable embryos by the total number of embryos analyzed.

\section{Effect of culture medium on seed germination}

Immature capsules were sterilized in $1 \% \mathrm{NaOCl}$ for 15 min, and then rinsed three times with sterile water. The seed capsules were then cleaved with a scalpel blade and 
the seeds were scraped off. The seeds were treated with $1 \% \mathrm{NaOCl}$ for $10 \mathrm{~min}$ and rinsed three times with sterile water. The disinfected seeds were then cultured on POM medium (Sigma, USA) modified with MS medium at 20 $\pm 2^{\circ} \mathrm{C}$ in the dark. Embryo swelling was defined as at least a doubling in size and formation of a protocorm. The numbers of swollen embryos were recorded after 12 weeks of culture by examination with a microscope.

\section{Statistical analysis}

All data were expressed as means \pm standard error (SE) analyzed using analysis of variance (ANOVA). Each experiment was replicated three times with at least 200 seeds per replication. Significant differences among the treatments were determined by performing multiple comparison tests using Duncan's multiple range test at $a \leq 0.05$ (SAS).

\section{Results and discussion}

Effect of $\mathrm{NaOCl}$ treatment on seed viability and germination

Viable embryos of $O$. coreana seeds turn red with tetrazolium chloride and $\mathrm{NaOCl}$ pre-treatment resulted in coloration of the embryos (Fig. 3A, B), while non-surviving embryos remained uncolored (Fig. 3C). Tetrazolium chloride (TTC) viability testing following different treatment times with $1 \% \mathrm{NaOCl}$ indicated that a 10 min resulted in $74.5 \%$ viability compared to the observed percentage of swollen embryos (84.4\%) and protocorm formation (81.5\%) after 12 weeks of culture (Table 1).

The effects on embryo swelling were first scored at 10 weeks (Fig. 3D) and indicated that this was a useful bioassay for estimating the viability of mature seed of terrestrial orchids, together with TTC staining. Pigment production could be an alternative to the standard chemical methods (Singh 1981; van Waes and Debergh 1986; Lauzer et al. 1994), particularly when the latter are not easily applied. Moreover, the coefficient of the bioassay staining was similar to that of the TTC and AF methods. The test worked well on seeds pretreated for more than $2 \mathrm{~h}$ in $10 \%$ $\mathrm{NaOCl}$, which generally promotes dormancy release in terrestrial orchid seeds (St-Arnaud et al. 1992; Malmgren 1996). Lauzer et al. (1994) pointed out that the TTC staining assay, based on the activity of dehydrogenases (MacKay 1972), could produce an over-estimation of Cypripedium acaule seed viability when seeds were subjected to a prolonged pretreatment. Pigment synthesis by fungi has frequently been reported in the context of seed coloration (Wicklow et al. 1987; McLean and Ray 1988) or fungal taxonomical characterization (Marrasas et al. 1998). In addition, inoculation of red fungi onto the seed
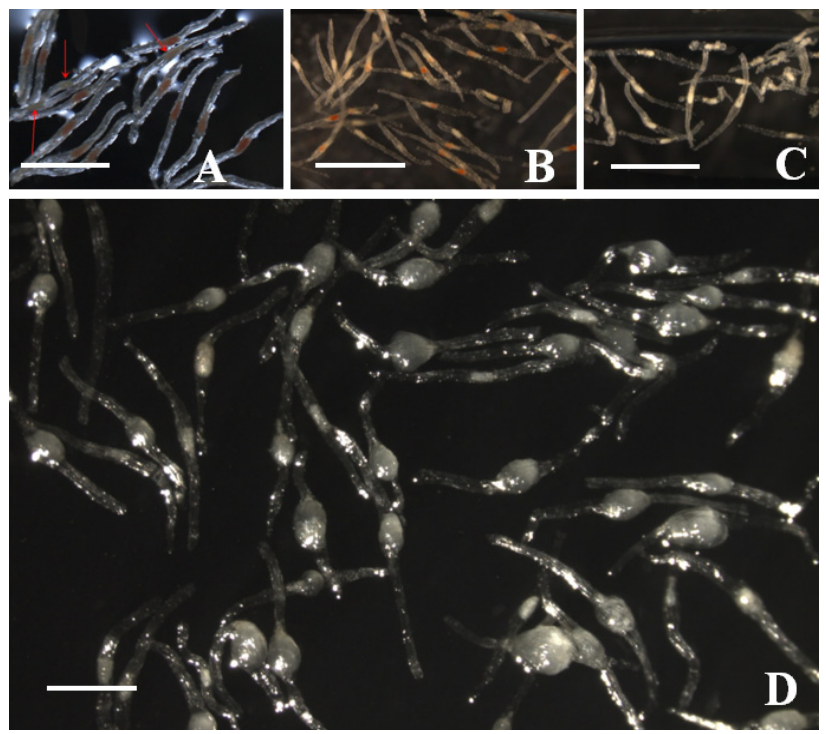

Fig. 3 Tetrazolium test and seed germination of $O$. coreana. Treatment of $1 \% \mathrm{NaOCl}$ for $0 \mathrm{~min}(\mathrm{~A}), 10 \mathrm{~min}(\mathrm{~B}), 60 \mathrm{~min}$ (C), Red arrows indicated survived embryos after treatment of $1 \% \mathrm{NaOCl}$ indicated treated time. D: Asymbiotically germinated seeds are white. Bars indicate 50 um

Table 1 Effect of treatment time of $1 \% \mathrm{NaOCl}$ on swelled embryo formation and protocorm formation from seed of $O$. coreana after 12 weeks of culture on POM medium supplemented with sucrose $20 \mathrm{~g} / \mathrm{L}$ and gerlite $3.0 \mathrm{~g} / \mathrm{L}$

\begin{tabular}{ccccccc}
\hline \multirow{2}{*}{$\begin{array}{c}\text { Treatment time } \\
(\mathrm{min})\end{array}$} & $\begin{array}{c}\text { Seed viability } \\
(\%)\end{array}$ & $\begin{array}{c}\text { Swelled embryos } \\
\text { formation }(\%)\end{array}$ & $\begin{array}{c}\text { Diameter of embryo } \\
\text { (um) }\end{array}$ & & $\begin{array}{c}\text { Protocorm formation } \\
(\%)\end{array}$ & $\begin{array}{c}\text { Diameter of protocorm } \\
\text { (um) }\end{array}$ \\
\hline 0 & $98.7 \pm 0.9 * \mathrm{a}$ & $32.8 \pm 2.7 * \mathrm{~b}$ & $21.6 \pm 6.9 \mathrm{~d}$ & & $25.2 \pm 2.8 \mathrm{~b}$ & $47.5 \pm 7.9 \mathrm{~d}$ \\
10 & $74.5 \pm 12.8 \mathrm{~b}$ & $84.4 \pm 7.7 \mathrm{a}$ & $88.4 \pm 4.9 \mathrm{a}$ & & $81.5 \pm 3.2 \mathrm{a}$ & $174.2 \pm 18.9 \mathrm{a}$ \\
30 & $14.9 \pm 5.4 \mathrm{c}$ & $15.3 \pm 2.6 \mathrm{c}$ & $67.1 \pm 3.9 \mathrm{c}$ & & $13.2 \pm 2.4 \mathrm{c}$ & $142.6 \pm 19.9 \mathrm{c}$ \\
60 & $2.6 \pm 0.7 \mathrm{~d}$ & $2.2 \pm 0.8 \mathrm{~d}$ & $72.9 \pm 8.9 \mathrm{~b}$ & & $1.8 \pm 0.4 \mathrm{~d}$ & $166.4 \pm 17.5 \mathrm{~b}$ \\
\hline
\end{tabular}

*Data are the means $\pm \mathrm{SD}$, of three experiments. Different alphabetical letters are significantly different according to Duncun's multiple range test at $\mathrm{P}<0.05$. 
at sowing has been suggested to extend fungal activity. The effectiveness of disinfection solutions such as $\mathrm{NaOCl}$ and $\mathrm{Ca}(\mathrm{ClO})_{2}$ for stimulation of germination of orchid seeds has been reported in some orchid species (Miyoshi and Mii 1998; St-Arnaud e tal. 1992, Malmgren 1996), but its mechanism has not yet been documented. Possible mechanisms of action underlying the induction of seed germination or breaking dormancy by $\mathrm{NaOCl}$ have been considered to be partial degradation of the seed coat and/or the solubilization and oxidation of some type of growth inhibitor. Harvais (1982) interpreted the stimulating effect of surface sterilization with $\mathrm{NaOCl}$ as a physiological effect of washing away the endogenous inhibitor abscisic acid (ABA) from the seeds.

\section{Effect of culture medium on seed germination}

The effect of $\mathrm{NaOCl}$ pre-treatment was examined on seed germination. When immature seeds of $O$. coreana, without $1 \% \mathrm{NaOCl}$ treatment, were cultured on POM medium,
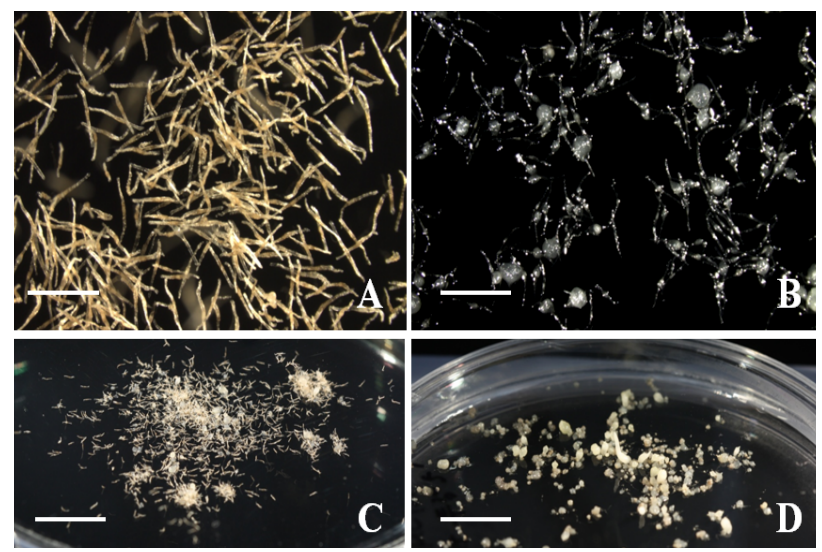

Fig. 4 Germination of mature seed from O. coreana. A-B: Treatment without $1 \% \mathrm{NaOCl}(\mathrm{A})$, with $1 \% \mathrm{NaOCl}$ (B) for 6 weeks C-D: Treatment without $1 \% \mathrm{NaOCl}$ (C), with $1 \%$ $\mathrm{NaOCl}$ (D) for 12 weeks D: $1 \% \mathrm{NaOCl}$ treated Development of germinated embryos. Bars indicate $20 \mathrm{um}$. they were not responsive at all during 8 weeks of culture (Fig. 4A). After culture for 12 weeks in POM medium, the seed swelling was very low in the untreated seeds compared to the seeds treated with $\mathrm{NaOCl}$ (Table 1, Fig. $4 C, D)$. In contrast, immature seeds pre-treated with $\mathrm{NaOCl}$ began to swell within 8 weeks (Fig. 4B). Seeds pre-treated with $\mathrm{NaOCl}$ on $\mathrm{POM}$ medium showed a greatly enhanced frequency of swollen embryos formed from immature seeds (Table 2). The frequency of embryo swelling from immature seeds reached $85.1 \%$ after 12 weeks of culture (Table 2). The maximum protocorm formation was recorded for the seeds treated with $1 \% \mathrm{NaOCl}$ for $10 \mathrm{~min}$ and cultured on POM medium (87.5\%), followed by $1 / 2 \mathrm{MS}$ (74.6\%), and MS (80.5\%), whereas $1 / 2 \mathrm{POM}(81.2 \%)$ was the least effective treatment medium for protocorm formation. The morphological development of $O$. coreana from seed to seedling was documented (Fig. 4D).

Seed germination of orchid species is typically very low or nonexistent in ex vitro and in vitro conditions (Ault and Blackmon 1987; Anderson 1996). Terrestrial orchids have more stringent requirements for germination but little is known about the specific requirements for each species (Fast 1982). $\mathrm{NaOCl}$ is a disinfecting agent that is widely used for seed surface sterilization (Bewley and Black 1994; Miyoshi and Mii 1998) and it is also known to favor seed germination or to overcome seed dormancy in some species (Vujanovic et al. 2000). In C. macranthos, the frequency of germination was $67 \%$ after sterilization with $\mathrm{NaOCl}$ (Miyoshi and Mii 1998). Yildiz and Celal (2002) reported that pre-treatment of Linum usitatissimum seeds with $\mathrm{NaOCl}$ for 20 minute enhanced germination. The promotion of germination by a $\mathrm{NaOCl}$ treatment is thought to be due to scarification of the seed coat, which allows more water and oxygen absorption or to the enhancement of oxidative respiration by an extra supply of oxygen arising from decomposition of $\mathrm{NaOCl}$ (Vujanovic et al. 2000).

In conclusion, we demonstrated that immature seeds of $O$. coreana showed enhanced viability and embryo swelling

Table 2 Effect of different culture medium on swelled embryo formation and protocorm formation from seed of $O$. coreana treated $1 \% \mathrm{NaOCl}$ for 10 minute after 12 weeks of culture

\begin{tabular}{cccccc}
\hline \multirow{2}{*}{ Culture medium } & \multicolumn{2}{c}{ Embryo stage } & & \multicolumn{2}{c}{ Protocorm stage } \\
\cline { 2 - 3 } \cline { 5 - 6 } & Swelled embryos formation (\%) & Diameter of embryo (um) & & Protocorm formation (\%) & Diameter of protocorm (um) \\
\hline $1 / 2 \mathrm{MS}$ & $78.2 \pm 1.9 * \mathrm{~b}$ & $77.8 \pm 1.9 \mathrm{c}$ & & $74.6 \pm 1.2 \mathrm{~d}$ & $181.6 \pm 4.6 \mathrm{~b}$ \\
$\mathrm{MS}$ & $74.6 \pm 6.3 \mathrm{c}$ & $81.4 \pm 3.2 \mathrm{~b}$ & & $80.5 \pm 1.2 \mathrm{bc}$ & $179.2 \pm 4.1 \mathrm{c}$ \\
$1 / 2 \mathrm{POM}$ & $72.2 \pm 1.8 \mathrm{~d}$ & $76.1 \pm 2.8 \mathrm{~cd}$ & & $81.2 \pm 2.6 \mathrm{~b}$ & $178.6 \pm 2.8 \mathrm{~cd}$ \\
POM & $85.1 \pm 6.1 \mathrm{a}$ & $87.1 \pm 5.3 \mathrm{a}$ & & $87.5 \pm 1.8 \mathrm{a}$ & $188.4 \pm 5.1 \mathrm{a}$ \\
\hline
\end{tabular}

*Data are the means $\pm \mathrm{SD}$, of three experiments. Different alphabetical letters are significantly different according to Duncun's multiple range test at $\mathrm{P}<0.05$. 
in response to a pre-treatment with $\mathrm{NaOCl}$, which resulted in a high frequency of germination of seeds of this orchid. This protocol offers could be used by commercial nurseries for large-scale propagation as well as for ex situ conservation of $O$. coreana.

\section{Acknowledgements}

This work was supported by the ministry of Environment as Eco-Star Project (No. 052-091-075).

\section{References}

Anderson AB (1996) The re-introduction of Platanthera ciliaris in Canada. In: Allen C. (Ed.). Proceedings of the North American Native Terrestrial Orchids: Propagation and Production. North American Native Terrestrial Orchid Conference Maryland:73-76

Ault JR, Blackmon WJ (1987) In vitro propagation of Ferocactus acanthodes (Cactaceae). Hort Science 22:126-127

Bae KH, Choi YE (2011) Factors affecting fruit baring in natural habitat and in vitro culture of zygotic embryos of Cypripedium japonicum. Prog Ornament Plant 11:146-152

Bae KH, Kim CH, Sun BY, Choi YE (2010) Structural changes of seed coats and stimulation of in vitro germination of fully mature seeds of Cypripedium macranthos Swartz by $\mathrm{NaOCl}$ pretreatment. Prog. Ornament. Plant 10:107-113

Bae KH, Kwon HK, Choi YE (2009) In vitro germination and plantlet conversion from the culture of fully mature seeds of Cypripedium guttatum Swartz. Prog Ornament Plant 9:160-165

Bewley, JD, Black M (1994) Seeds. Physiology of development and Germination. Second Edition New York, Prenum Press

Dutra D, Kane ME, Richardson L (2009) Asymbiotic seed germination and in vitro seedling development of Cyrtopodium punctatum: a propagation protocol for an endangered Florida native orchid. Plant Cell Tiss Org Cult 96:235-243

Fast G (1982) European terrestrial orchids. Symbiotic and asymbiotic methods. In: Arditti J, ed. Orchid biologyreviews and perspectives II. Ithaca, NY: Comstock Publishing Associates 326-329

Finet EA (1908) Oreorchis coreana sp. nov. Bull Soc Bot Fr $55: 337$

Harvais G (1982) An improved culture medium for growing the orchid Cypripedium reginae axienically. Can J Bot 51: 327-332

Harvais G, Hadley G (1967) The relation between host and endophyte in orchid mychorriza. New Phytol 66:205- 215

IUCN (2009) IUCN Red List of treated species. Prepared by the IUCN Species Survival Commission. IUCN, Gland, Switzerland, http://www.iucnredlist.org
Lakon, G (1949) The topographical tetrazolium method for determining the germinating capacity of seeds. Plant Physiol 24:389-394

Lauzer D, St-Arnaud M, Barabe D (1994) Tetrazolium staining and in vitro germination of mature seeds of Cypripedium acaule (Orchidaceae). Lindleyana 9:197-204

Lee, JS, Choi BH (2006) Distribution and red data of wild orchids in the Korean Peninsula. Kor J Plant Taxon 36:335-360

Lee TB (1984) Outline of Korean endemic plants and their distribution. Kor J Plant Taxon 14:21-32

Lee WT (1996) Lineamenta Florae Koreae. Academy Press, Seoul

Lee YN (2006) Flora of Korea. Gyohaksa, Seoul

MacKay DB (1972) The measurement of viability. In: Roberts EH, ed. Viability of seeds. Syracuse, New York Syracuse University Press, pp 172-208

Maekawa, F (1935) Diplolabellum coreanum. J Jpn Bot 11:305 Malmgren S (1996) Orchid propagation: theory and practice. In: Allen, C. (Ed.), Proceedings of the North American Native Terrestrial Orchids: Propagation and Production. North American Native Terrestrial Orchid Conference, Maryland, pp 63-71

Marasas WFO, Rheeder JP, Logrieco A, van Wyk PS, Juba JH (1998) Fusarium nelsonii and F. musarum: two new species in section Arthrosporiella related to $F$. camptoceras. Mycologia 90:505-513

McLean KS, Ray KW (1988) Purple seed stain of soybean caused by isolates of Cercospora kikuchii from weeds. Can J Plant Path 10:166-171

Miyoshi K, Mii M (1998) Stimulatory effects of sodium and calcium hypochlorite, pre-chilling and cytokinins on the germination of Cypripedium macranthos seed in vitro. Physiol Plant 102:481-486

Murashige T, Skoog F (1962) A revised medium for rapid growth and bioassays with tobacco tissue cultures. Physiol Plant 15:473-497

Paik WK (1999) The status of endemic plants in Korea and our tasks in the $21^{\text {st }}$ century. Kor J Plant Taxon 29:263-273

Rasmussen HN (1992) Seed dormancy patterns in Epipactis palustris (Orchidaceae): Requirements for germination and establishment of mycorrhiza. Physiologia Plantarum 86: 161-167

SAS, Institute Inc. 2003. SAS version 9.0. SAS Institute, North Carolina

Singh F (1981) Differential staining of orchid seeds for viability testing. American Orchid Soc Bull 50:416-418

Stewart SL, Kane ME (2006a) Asymbiotic germination and in vitro seedling development of Habenaria macroceratitis (Orchidaceae), a rare Florida terrestrial orchid. Plant Cell Tiss Org Cult 86:147-158

Stewart SL, Kane ME (2006b) Symbiotic germination of Habenaria macroceratitis (Orchidaceae), a rare Florida terrestrial orchid. Plant Cell Tiss Org Cult 86:159-167

Stewart SL, Kane ME (2007) Symbiotic seed germination and evidence for in vitro mycobionts specificity in Spiranthes 
brevilabris (Orchidaceae), and its implications for specieslevel conservation. In Vitro Cell Dev Biol Plant 43:178-186

St-Arnaud MD, Lauzer D, Barabe D (1992) In vitro germination and early growth of seedlings of Cypripedium acaule (Orchidaceae). Lindleyana 7:22-27

Suzuki RM, Moreira VC, Nakabashi M, Ferreira WM (2009) Estudo da germinação e crescimento in vitro de Hadrolaelia tenebrosa (Rolfe) Chiron \& V.P. Castro (Orchidaceae), uma espécie da flora brasileira ameaçada de extinção. Hoehnea 36:657-666

van Waes, JM, Debergh PC (1986) In vitro germination of some western European orchids. Physiol Plant 67:253-261

Vujanovic V, St-Arnaud M, Barabe D, Thibeault G (2000) Viability testing of orchid seed and the promotion of colouration and germination. Ann Bot 86:79-86

Wicklow DT, Bennet GA, Shotwell OL (1987) Secondary invasion of soybeans by Fusarium graminearum and resulting mycotoxin contamination. Plant Disease 71:1146

Yildiz M, Celal ER (2002) The effect of sodium hypochlorite solution on in vitro seedling growth and shoot regeneration of flax (Linum usitatissimun). Natul wissen schffen 89: 259-261 